Res Publica. Revista de Historia de las Ideas Políticas

ISSN: $1576-4184$

http://dx.doi.org/10.5209/RPUB.56466

\title{
Política escatológica y economía salvífica en el cristianismo medieval: evasiones en la genealogía foucaultiana de la gubernamentalidad
}

\author{
Cristina Catalina*
}

Recibido: 20 de julio 2016 / Aceptado: 10 de mayo de 2017

Resumen. Este artículo analiza la dimensión escatológica en la constitución del pastorado eclesiástico plenomedieval en un diálogo con la analítica del poder de Michel Foucault. Para ello se examina la especificidad medieval de la economía de salvación y la política escatológica de la Iglesia romana y de los movimientos de resistencia que surgen en sus márgenes. En paralelo al estudio histórico, se reflexiona sobre las caracterizaciones del pastorado eclesiástico medieval que ofrece Foucault en la genealogía de la gubernamentalidad. Finamente, se argumenta que la temporalidad escatológica que inaugura el cristianismo condiciona la forma de dominación juridizada y pastoral que adopta la Iglesia. Esta dualidad gubernativa, que culmina en el periodo medieval con la aspiración a una potestad absolutista, se manifestará de forma especialmente patente en la política de persecución de la herejía.

Palabras clave: Poder pastoral; escatología medieval; cristianismo medieval; Foucault; herejía.

\section{[en] Political escatology and economy of salvation in medieval christianity: evasions in the foucaultian genealogy of governmentality}

\begin{abstract}
This paper analyses the eschatological dimension of the constitution of the ecclesiastical pastorate between the $11^{\text {th }}$ and $13^{\text {th }}$ century. With this purpose, it sets up a dialogue with Michel Foucault's analytics of power. Thus, it examines the economy of salvation characteristic of the medieval Roman church, as well as the movements of resistance that emerged at its margins. In parallel to the historical study, the paper evaluates how the foucaultian genealogy of governmentality conceives the medieval pastorate. Finally, it argues that the eschatological temporality launched by Christianity characterizes the way in which the Church exercises a legalised and pastoral power. This governmental duality culminates with the papal aspiration to an absolutist power and is most clearly revealed in the persecution of heretics.
\end{abstract}

Keywords: Pastoral power; medieval eschatology; medieval Christianity; Foucault; heresy.

Sumario: 1. Introducción. 2. La analítica del pastorado y el cristianismo en Michel Foucault. 3. La institución del pastorado eclesiástico en la Edad Media. 4. La ratio del gobierno pastoral: economía salvífica y temporalidad escatológica. 5. El modelo escatológico del pastorado medieval. 6. Contra-modelos escatológicos y salvíficos. 7. Conclusiones

Cómo citar: Catalina, C. (2017). Política escatológica y economía salvífica en el cristianismio medieval: evasiones en la genealogía foucaultiana de la gubernamentalidad, en Res publica 20.2, 207-225.

Consejo Superior de Investigaciones Científicas (CSIC)

ccatalinag@gmail.com 


\section{Introducción}

La constitución eclesiástica medieval supone un hito importante en la historia de las formas políticas en Occidente en tanto que institución dual de gobierno y soberanía. En este periodo, la Iglesia romana sentó las bases de los futuros sistemas jurídicos europeos a través de la creación de una potestad jurisdiccional centralizada y reticular en la que se imbricaron prácticas complejas de cura de almas y administración sacramental. En este artículo, se investiga esta constitución política del cristianismo medieval a través de un diálogo entre la analítica del pastorado de Foucault y la conceptualización de la economía de salvación cristiana.

En primer lugar, se estudia la analítica foucaultiana del cristianismo y del pastorado cristiano al hilo de los análisis genealógicos sobre la gubernamentalidad ${ }^{1}$. Reflexionaremos sobre el rechazo de las dimensiones escatológica y salvífica como principios de intelección del pastorado y sobre el hecho de que recurra a ellas cuando analiza el paso de la temporalidad escatológica medieval — basada en una economía de salvación - a la moderna temporalidad gubernamental — basada en la lógica del arte político y la economía política-. En un segundo lugar, se plantea la utilidad analítica del concepto de escatología a través del estudio de un caso histórico: la Iglesia romana que inaugura la revolución gregoriana y otras economías de salvación que surgen en sus márgenes entre los siglos XI y XIII. Se argumenta que la Iglesia medieval posee un trasfondo escatológico incluso a pesar de su desarrollado proceso de institucionalización y jurisdiccionalización, y que, por tanto, la escatología no es sólo propia de algunos movimientos de contra-conducta pastoral. En tercer lugar, se muestra que la pertinencia de esta conceptualización es manifiesta cuando se trata de explicar la diferencia entre las técnicas pastorales de conducción de almas - el gobierno eclesiástico medieval — y las técnicas de gestión de hombres y cosas - el gobierno estatal sobre las poblaciones-.

En el cuarto apartado se expone el tipo de política escatológica y de economía salvífica que desarrolla la Iglesia medieval: por un lado, la interiorización y espiritualización de la salvación y, por el otro, la co-dependencia entre la redención individual y la cristianización universal, cuyos efectos serán la obligación jurídica de participar en los sacramentos eclesiásticos y la persecución criminal de la herética parvedad. El último lugar, se analizarán algunas contra-economías de salvación medievales para mostrar que existe un locus conflictivo político-gubernativo en el pastorado cristiano y no sólo pastoral como establece Foucault. Éste reside en las potestades que detenta la Iglesia como interceptora entre el reino de dios y los hombres - como vicariatoy en las competencias profanas que despliega en su institucionalización.

\section{La analítica del pastorado y el cristianismo en Michel Foucault}

Foucault aborda el cristianismo desde el punto de vista de la historia del sujeto occidental y de la genealogía de la gubernamentalidad. De modo que no ofrece un

En este artículo nos centraremos en el fenómeno y la noción del pastorado porque recoge especialmente la dimensión institucional de la conducta de almas. Por ello, y porque es el texto con más referencias al pastorado pleno-medieval, casi todas nuestras referencias a M. Foucault provienen del curso del Colegio de Francia de 1977-78, editado en castellano como Seguridad, Territorio y Población. M. Foucault, Seguridad, territorio y población, Madrid, Akal, 2008. 
análisis sistemático, sino una analítica fragmentaria que deriva de los estudios sobre la disciplina, la normalización, la gubernamentalidad moderna o los regímenes de verdad. Sin embargo, hay un elemento común que atraviesa estos fragmentos y constituye, para Foucault, la particularidad del cristianismo²: la ligazón del hombre con una verdad de sí que se revela en un examen de conciencia guiado. Se trata de la confesión cristiana como revelación de una verdad de sí descubierta por medio de una introspección guiada por un pastor, por un otro cualificado ${ }^{3}$. El cristianismo es una religión de confesión, pero su originalidad la constituye también el hecho de que se organiza en una institución pastoral. Así, es la categoría de poder pastoral o pastorado la que, en efecto, describiría esta particularidad del cristianismo.

Desde la perspectiva genealógica de Foucault, el poder pastoral constituye la matriz del gobierno de las poblaciones del Estado gubernamental. Ambas, gobierno pastoral y gobierno político, compartirían técnicas y procedimientos de dirección o conducta de los hombres. Esto hace del poder gubernativo - tanto el pastoral como el político - un modelo diferente al de la soberanía - tanto feudal como modernacaracterizada por el dominio territorial y legal. Desde este punto de vista, la idea de gubernamentalidad pone de manifiesto que ciertos principios de conducta de hombres del gobierno pastoral cristiano no desaparecen tras el fin de la Edad Media, sino que se resignifican al hibridarse con las formas de poder soberano-legal del Estado administrativo, como la disciplina y policía ${ }^{4}$. El resultado del proceso será el Estado gubernamental regido por el arte político del gobierno de los hombres cuyo poder se ejerce mediante dispositivos de seguridad sobre una masa de población. En este umbral del siglo XVII se transforman y expanden los dispositivos y prácticas pastorales, imbricándose en los propios de la soberanía estatal —el sistema diplomático militar y la policía- - emerge entonces la gestión de la población ${ }^{5}$. Subsiguientemente, el poder gubernativo a partir del siglo XVIII se regirá por la racionalidad gubernamental, por la regulación securitaria de las poblaciones y no ya por la conducción pastoral de almas.

En el mismo curso de 1978, en las clases del 8 y el 15 de marzo, Foucault se refiere a este umbral de época recurriendo a un vocabulario un tanto distinto al que emplea en las clases en las que analiza el pastorado. Cuando analiza la emergencia histórica del Estado moderno, explica que la razón de Estado — ratio status - supuso una ruptura de la temporalidad escatológica y la economía de salvación del pastorado cristiano medieval. En este sentido, Foucault considera que el gobierno político regido por la razón de Estado:

no deberá preocuparse por la salvación de los individuos. Ni siquiera tendrá que buscar nada semejante a un fin de la historia, una consumación, un punto donde se articulen el tiempo de la historia y la eternidad. Por consiguiente, nada parecido a ese sueño del último Imperio que había gobernado las perspectivas religiosas e históricas de la Edad Media. Después de todo, en el medioevo todavía estábamos inmersos en un tiempo que en cierto momento debía convertirse en un tiempo unificado, el tiem-

Una particularidad que ha creado una impronta en la historia de la subjetividad occidental. M. Foucault, $E l$ gobierno de los vivos. Curso del Collège de France (1979 1980), Madrid, Akal, 2016, pp. 100-101.

L'aveu: confesión, pero con el matiz de ser una revelación, una confidencia de algo que previamente se reconoce. M. Foucault, Seguridad, Territorio y Población, op.cit., pp.187-225.

Ibidem, p. 229. 
po universal de un Imperio en el cual todas las diferencias se borrarían, un Imperio universal que anunciaría el retorno de Cristo y sería el teatro donde éste habrá de acaecer. El Imperio, el último Imperio, el Imperio universal fuera el de los Césares o el de la Iglesia, era con todo algo que recorría el punto de vista de la Edad Media, y en esa medida no había gobierno indefinido. No había Estado o reino condenado de manera indefinida a la repetición en el tiempo. Ahora, al contrario, nos encontramos en una perspectiva en que el tiempo de la historia es indefinido. Es lo indefinido de una gubernamentalidad para la cual no se prevé término ni fin. Estamos en la historicidad abierta, a causa del carácter indefinido del arte político ${ }^{6}$.

Foucault está planteando que la temporalidad que inaugura el Estado moderno supuso el abandono de la racionalidad salvífica y la temporalidad escatológica medievales ${ }^{7}$. La experiencia cristiana medieval amparaba expectativas mesiánicas de la segunda venida, cuyo acontecer depende del afuera del tiempo, aunque éste fuera retardado infinitamente. Por ello, se puede hablar de una temporalidad basada en la perspectiva escatológica de la salvación. Efectivamente, la querella entre la Iglesia y el Imperio fue también una disputa por presentarse como la potestas del tiempo universal antecesor del final. En este sentido, la racionalidad del gobierno político estatal, inmanente e indefinida, rompe con la temporalidad definida y la racionalidad dual trascendente-inmanente que impone el trasfondo escatológico de la economía de salvación ${ }^{8}$.

A pesar de esta interpretación del umbral de época medieval-moderno en términos de transferencias, matrices y rupturas, Foucault no recurre al vocabulario de querella de la secularización ${ }^{9}$. En esta línea, incluso para analizar el pastorado, rehúsa al dualismo trascendencia/inmanencia o espiritual/temporal, ambos ineludibles en la conceptualización del cristianismo como religión de salvación, de la teología trinitaria y su trasfondo escatológico ${ }^{10}$. Subyace aquí una prevención metodológica e interpretativa sobre la explicación de lo positivo desde su afuera, por ello, pretende abordar la historicidad de la Iglesia evitando recurrir a la perspectiva de la historia como historia de salvación cristiana ${ }^{11}$. Con la categoría de pastorado pretende además distanciarse de la concepción de la creencia religiosa como ideología, como el reflejo de un interés o aspiración particular de un grupo o clase ${ }^{12}$ y no caer en

Ibidem, p. 249.

Ibidem, p. 219: "Hoy querría pasar, por fin, de la pastoral de las almas al gobierno político de los hombres. (...) de esa economía de las almas al gobierno de los hombres y las poblaciones".

$8 \quad$ M. Senellart, "Michel Foucault: une autre histoire du christianisme?" en Bulletin du centre d'études médiévales d'Auxerr, 7, 2013, pp. 1-15. Consultado el 28 de marzo de 2015, pp. 5-6.

9 Para una visión general del debate sobre la secularización, véase: A. Rivera, "La secularización después de Blumenberg", en Res publica, 11-12, 2003, pp. 95-142.

10 M. Weber, Sociología de la religión, Madrid, Akal, 2012.

11 Pero no todos los análisis caen necesariamente en esta concepción de la historia cuando interpretan la Iglesia en su desarrollo histórico como una institución de salvación. Cf. H. Blumenberg, La legitimidad de la modernidad, Valencia, Pre-textos, 2008, p. 52: "El concepto de historia tendría que ver con un plazo de gracia, no con una esperanza dirigida hacia el futuro y que busca en él su realización. Los acontecimientos del fin se convierten en un secreto que pesa sobre la historia y que es reservado a Dios, lo cual, más que para confortar a la conciencia humana con su decisión en el tema de la salvación, sirve para que Dios justifique el no haber dispensado a los cristianos, frente a los paganos, de los efectos de su cólera, cargando sobre sus espaldas el precio por la implorada supervivencia de un genus humanum que sigue sin diferenciar entre elegidos y réprobos".

12 M. Foucault, Seguridad, territorio y población. op. cit., pp. 217-218. 
un reduccionismo de la institución, en este caso a Iglesia, a su objetividad jurídica y organizativa o a su funcionalidad social. En contraposición a esta tradición analítica, Foucault apuesta por un análisis empírico de las técnicas y procedimientos efectivos de poder que desarrolla la Iglesia históricamente, así como de los saberes y los efectos de subjetivación que produce. El pastorado como estrategia y táctica de gobierno ${ }^{13}$.

Foucault acierta al plantear que la dimensión escatológica y la racionalidad salvífica no son privativas de la Iglesia, sino que atraviesan otras instituciones y conceptos medievales como el Imperio. Escatología y salvación no son propias de la organización pastoral eclesiástica sino de una época que inaugura el cristianismo y alcanza hasta el umbral del siglo XVII, hasta la emergencia del gobierno político y la racionalidad económica e indefinida. El inconveniente de esta operación es que acaba prescindiendo de estas dimensiones en la analítica del pastorado ${ }^{14}$. La economía de salvación que ofrece la teología trinitaria cristiana produce efectos constitutivos de poderes fácticos, pero que están ineludiblemente atravesados por la tensión espiritual/temporal en tanto la división de poderes le es interna. El reconocimiento de la existencia de un resto profano de poder tiene implicaciones tanto sobre la relación que la comunidad cristiana mantiene con las potestades seculares como sobre su dimensión mundana en tanto organización espiritual en el mundo. Una tensión que atraviesa el pastorado desde sus inicios.

Esta postura lleva a Foucault a abordar el pastorado desplazando a segundo plano el acontecimiento venidero del Juicio divino —-salvación-, el problema exegético de los textos sagrados y la enseñanza del dogma — verdad- y, en último lugar, el acatamiento de del mandamiento divino e interpretación de su voluntad — leySi bien acepta cierto momento de verdad en estos tres principios tradicionales de la heurística del cristianismo - salvación, ley y verdad-, insiste en que lo verdaderamente característico del cristianismo son las relaciones de poder y los efectos de individuación que producen. En este sentido, el principio de la salvación produjo relaciones basadas en una economía de méritos y deméritos cuyo efecto es la subjetivación por identificación analítica. La centralidad de la ley implicó el establecimiento de una forma de obediencia absoluta cuyo efecto fue la subjetivación por sujeción ${ }^{15}$. Por último, la relación con la verdad, dogma y catequesis, constituyó para Foucault un dominio de sí que pasa por la exclusión del yo.

Es conveniente resaltar la organización institucional de la Iglesia como uno los rasgos fundamentales que hacen de la religión cristiana un pastorado. Las diferentes técnicas y procedimientos de conducta de almas —oikonomia psychon ${ }^{16}$ - se imbrican y desarrollan en esta compleja organización institucional. La disposición de las

13 Foucault consideró que la historia de la Iglesia se había centrado en el estudio de sus instituciones, las doctrinas y creencias y prácticas religiosas y, que, sin embargo, no había tenido lugar una reflexión sobre las técnicas empleadas en su historia y los saberes ligados al ejercicio del pastorado. Ibidem, p. 152-153.

14 M. Senellart ha señalado que Foucault deja de lado tres problemas importantes la interpretación del cristianismo: el momento histórico de la fundación, la dimensión escatológica y la tensión entre poder espiritual y temporal. M. Senellart, op. cit., pp. 1-15, aquí p. 3

15 M. Foucault, Seguridad, territorio y población, op. cit., pp. 173-174: "La figura del pastor no es un enunciador de la ley o un juez, sino más bien un médico, un curador de almas. No hay tampoco una sola voluntad de Dios o una ley universal sino voluntades que rigen para cada hombre, de tal modo que la acción del pastor se individualiza y establece una relación de sometimiento con cada oveja en la que éste, el sometimiento, no tiene finalidad más allá de la obediencia".

16 Ibidem, p. 187. 
técnicas de cura de almas en una institución eclesiástica es para Foucault propia del cristianismo y, realmente, le fascina. En la clase del 15 de marzo de 1978 dice:

el pastorado comienza con un proceso que es absolutamente único en la historia y del que no se encuentra ningún ejemplo en ninguna otra civilización: un proceso por el cual una religión, una comunidad religiosa, se constituyó como Iglesia, es decir, como una institución con pretensiones de gobierno de los hombres en su vida cotidiana, so pretexto de conducirlos a la vida eterna en otro mundo, (...) eso es la Iglesia, y no existe ningún otro ejemplo en la historia de las sociedades. Creo que con esta institucionalización de una religión como Iglesia se forma $-\mathrm{y}$ debo decirlo de una manera bastante sucinta, al menos en sus grandes líneas - un dispositivo de poder sin paralelo en ningún otro lugar ${ }^{17}$.

\section{La institución del pastorado eclesiástico en la Edad Media}

Foucault caracteriza la organización institucional del pastorado con dos rasgos: el dimorfismo o diferenciación entre clérigos ordenados y laicos, y la definición progresiva de los poderes sacramentales de la Iglesia ${ }^{18}$. La cristalización de estos dos fenómenos tiene lugar durante el periodo medieval en la Iglesia romana, cuya forma institucional surge a partir de revolución papal de los siglos XI y XII — también denominada reforma gregoriana ${ }^{19}$ - Gregorio VII quiso imponer la supremacía jurisdiccional y la primacía gubernativa del papado sobre toda la Cristiandad latina en condición de vicario de Pedro. Puso así las bases para el desarrollo del proyecto teocrático del papado de Inocencio III en la primera mitad del siglo XIII. Al transformarse el vicariato petrino en un vicariato de Cristo o divino, la eclesiología prescinde de la mediación apostólica y profundiza la divinización de la figura pontifical. Este cambio fue importante en el desarrollo de la noción de plenitudo potestatis del papado - ya anunciada por Gregorio VII-, puesto que la divinización del oficio pontifical abre el paso para la absolutización de la potestad papal. Sobre estas bases se construirá el problema de la herejía como un crimen contra la Iglesia y la política de erradicación en el interior de la cristiandad ${ }^{20}$.

El pastorado eclesiástico alcanza entonces un desarrollo institucional -administrativo y jurídico - de tal magnitud que rebasa su racionalidad como gobierno e inaugura un poder jurisdiccional insólito. El propio Foucault afirma que la Iglesia medieval adopta un modelo judicial que, en principio, no es propio del poder pastoral, sino un rasgo externo a su racionalidad y propio del modelo de la soberanía ${ }^{21}$. La introducción del modelo judicial en la pastoral se manifiesta para Foucault en los

\footnotetext{
M. Foucault, Seguridad, territorio y población, op. cit., p. 150.

Ibidem, pp. 199-200.

19 Cf. H. Bermann. La formación de la tradición jurídica de occidente. México DF, Fondo de Cultura Económica, 2001. H. Bermann interpretó las transformaciones promovidas por el papado a partir del siglo XI como la primera revolución jurídica europea. La revolución papal dio lugar a una institución jurisdiccional y reticular sobre la base de una administración pastoral territorial, centralizada y jerárquica, gobernada a través del nuevo derecho canónico.

20 J. Théry, "Le gouvernement romain de la Chrétienté autour de 1206: Innocent et les debuts de la théocratie pontificale", en Dominique, avant les dominicains. Mémoire dominicaine, 21, 2007, pp. 33-38, aquí p. 37.

21 M. Foucault, Seguridad, territorio y población, op. cit., p. 201.
} 
penitenciales medievales: el sacramento de la penitencia que debería estar basado en una corrección purgativa en consonancia con el modelo del pastor-médico, introduce sin embargo la corrección punitiva propia del ámbito judicial o las penas tarifadas propias de la resolución de conflictos de raíz germánica.

No obstante, la presencia de rasgos de la soberanía en el pastorado eclesiástico supera la mera incorporación del modelo judicial en la cura de almas. El pastorado se sostiene institucionalmente sobre la nueva potestad legislativa y judicial que concibe al papa como legislador y juez supremo. Esto implicó tanto la jurisdiccionalización de los sacramentos ${ }^{22}$ como la sacramentalización de las formas punitivas ${ }^{23}$. Este fenómeno ha sido estudiado por P. Prodi ${ }^{24}$ desde la tensión constitutiva entre el foro interno — divino - de la culpa y el foro externo - eclesiástico — de la infracción. El primero atañe al ámbito de la conciencia, siendo susceptible de ser juzgado únicamente por Dios, mientras que el segundo pertenece al ámbito de la ley positiva cuya infracción debe ser juzgada por la Iglesia. Durante la revolución gregoriana esta tensión se agudiza al abrogarse el papado la capacidad de juzgar el foro interno. Mientras que así la diferencia entre crimen y pecado se hace menos nítida en la praxis, es precisada conceptualmente en el ámbito de la teología moral y el derecho canónico. Las prevenciones metodológicas que hacen a Foucault obviar el problema de la división de poderes en el seno del cristianismo, impiden interpretar la presencia de los rasgos jurídicos en la Iglesia como una manifestación de una tendencia intrínseca a la organización del pastorado cristiano. No obstante, se ha demostrado que la existencia ineludible del resto profano de poder en el marco de la teología trinitaria implicó que el pastorado dispusiera de una política y una economía de salvación en la tierra.

\section{La ratio del gobierno pastoral: economía salvífica y temporalidad escatológica}

Desde la concepción foucaultiana se podría afirmar que la Iglesia medieval, al integrar el modelo judicial en el pastorado, dispone de un poder dual: el gubernativo-pastoral y el soberano-legal. Surgen así dos preguntas: 1) ¿Qué explica la diferencia entre la Iglesia medieval y el Estado gubernamental moderno, a pesar de que ambos son una institución dual de gobierno y soberanía con rasgos muy diferentes? Y, por lo tanto, 2) ¿En qué se fundamenta la diferencia entre las técnicas de gobierno de cada institución: la dirección o conducta pastoral medieval y la moderna gestión securitaria de las poblaciones?

Se ha anticipado anteriormente la respuesta que emerge del propio texto de Foucault, en la que es patente el vocabulario de la escatología de salvación cristiana. El arte político de la razón de Estado y, posteriormente, la gestión de poblaciones rompe con el horizonte salvífico y escatológico que atraviesa el Medioevo. Mientras que el pastorado medieval se rige por la economía de salvación y por una temporalidad

22 Por ejemplo, el bautismo se asemejará a un rito de introducción a la condición de súbito de la Iglesia con derechos y deberes o el ordenamiento canónico a un estatuto jurídico particular. Igualmente, el sacramento de la penitencia recodará a un proceso judicial, la confesión como interrogatorio y sentencia judicial.

23 Por ejemplo, la introducción de la confesión en un proceso judicial de investigación como técnica de desvelamiento de un pecado que será juzgado criminalmente. También el hecho de que el clero ordenado sea castigado con penas correctivas cuando es condenado por simonía y nicolaísmo.

24 Cf. P. Prodi. Una storia della giustizia: dal pluralismo dei fori al moderno dualismo tra coscienza e diritto. Bolonia, Il Mulino, 2001. 
escatológica — cerrada - el moderno gobierno de poblaciones lo hace por la economía política y la temporalidad ilimitada de la gestión de hombres y cosas. La naturaleza de un cosmos divinizado cuya ratio reside en una dinámica entre trascendencia e inmanencia, es desplazada por la naturaleza de la gestión de cosas y hombres cuya ratio es indefinida e inmanente. El horizonte cerrado de la salvación y sus promesas desaparecen ante el nuevo horizonte abierto, carente de expectativas extra-mundanas $^{25}$. Desde este punto de vista, resulta difícil entender por qué Foucault para conceptualizar el pastorado cristiano rehúsa recurrir a la dimensión escatológica: a la economía de salvación, a la experiencia trascendente del tiempo o a la división de poderes. Puesto que, incluso si se admite con Foucault que el trasfondo escatológico atraviesa toda una época y no es sólo propio del pastorado, esta dimensión se inaugura en la génesis de la teología trinitaria cristiana — como respuesta a la teología imperial romana ${ }^{26}$-.

Senellart ${ }^{27}$ ha planteado que esta contradicción en Foucault deriva del empleo de la noción de escatología en el estudio de las resistencias al pastorado. Cuando analiza las contra-conductas pastorales reduce el significado de escatología a la actitud milenarista y al fenómeno de la temporalización ${ }^{28}$ — lo que no hace cuando se refiere al umbral de época-. Pero esta equiparación no resulta sostenible desde una perspectiva historiográfica ${ }^{29}$. La escatología, entendida como creencia en la existencia del final del tiempo mundano, no implicó de suyo la convicción ni de que la llegada fuera inminente ni en el advenimiento de una era dorada en la tierra, los mil años de bonanza terrenal previos al final de los tiempos tras la segunda venida del Mesías. Por último, tampoco implicó la idea de que dicha época de perfección espiritual o purificación de la humanidad pudiera ser realizada por un grupo de elegidos en el más acá.

La creencia en el fin del mundo es propia del cristianismo e implica un trasfondo apocalíptico en sus diferentes formas de organización, una tensión constante que lo atraviesa, aunque no se exprese inequívocamente como milenarismo o temporalización. Para H. Blumenberg ${ }^{30}$ lo que precisamente caracteriza a la Iglesia en su desarrollo institucional es el retraso del fin de los tiempos y de la parusía. Históricamente esto

25 M. Foucault, Seguridad, territorio y población, op. cit., p. 229: "Un mundo enteramente finalista, un mundo centrado en el hombre, un mundo de prodigios, maravillas y signos, un mundo para terminar de analogías y cifras; esto constituye la forma manifiesta de un gobierno pastoral de Dios sobre el mundo. Ahora bien, ¿en qué época desaparece esta situación? Exactamente entre 1580 y 1650, en el momento de la fundación de la episteme clásica".

26 Sobre la división de poderes en el cristianismo, véase: J.L. Villacañas, Teología política imperial y comunidad de salvación cristiana. Una genealogía de la división de poderes, Madrid, Trotta, 2016; también: P. Prodi. Una storia della giustizia: dal pluralismo dei fori al moderno dualismo tra coscienza e diritto, Bologna, Società editrice il Mulino, 2000.

27 M. Senellart, op. cit., pp 1-15, aquí p. 6.

28 Véase la nota 56.

29 J. Le Goff, La civilización del Occidente medieval, Barcelona, Paidós, 2008, p. 164: "El detalle histórico de esta creencia [el sueño de un millenium] es complejo. El milenarismo es un aspecto de la escatología cristiana, se inserta en la tradición apocalíptica y está estrechamente vinculado al mito del Anticristo".

$30 \quad$ H. Blumenberg, La legitimación de la Edad Moderna, Valencia, Pre-textos, 2008, pp. 51-52: "El futuro escatológico no sólo se había convertido en algo indeterminado, sino que había perdido incluso la relación con los bienes de la salvación, ya trasferidos a la humanidad redimida. El sentimiento escatológico fundamental de la época cristiana ya no podría consistir en la esperanza de acontecimientos que llegarían al final de los tiempos, sino únicamente en el miedo ante el Juicio y la destrucción del mundo. Si la comunidad cristiana primitiva había calmado aún por la venida de su Señor, pronto la Iglesia pedirá pro mora finis, por el aplazamiento del final”. 
supuso el paso de una comunidad escatológica primitiva a una institución de salvación que instaura una nueva economía salvífica y posterga el cumplimiento de las promesas. La Iglesia aplaza el fin, pero sin negarlo; lo que ocurre es que progresivamente subordina las promesas a la participación en la economía de salvación canónico-eclesiástica ${ }^{31}$. Finalmente, desarrollará un universalismo cristiano en el seno de la economía de salvación trinitaria que, mientras se representa como garante del acontecimiento futuro de un reino celeste, se organiza en base a una escatología anti-apocalíptica.

La revolución papal impone como única vía salvífica la participación en los sacramentos canónicos ofrecidos por la corporación del clero ordenado en cuya cúspide está el gobierno papal ${ }^{32}$. La evolución histórica de la institución eclesiástica cristiana implicó una progresiva mundanización ${ }^{33}$ cuya culminación es papado de Gregorio VII al proyectar la institucionalización de la iglesia a semejanza de la Ciudad de Dios. La ambición de la potestad papal empuja hasta el límite de pretender anticipar el juicio de Dios en la tierra. El papado reclama competencias canónicas para la absolución de pecados en confesión, en el nuevo espacio del purgatorio y mediante la concesión de indulgencias. Ofrece así una purificación obligatoria para todos y cada uno de los fieles, que garantiza la salvación a la Cristiandad universal y unitaria en el fin. A pesar de este particular proceso de mundanización que implicó una experiencia del tiempo inmanente y mundana, las promesas de salvación y su realización siguieron perteneciendo al misterio divino y, por ello, al mismo tiempo rige la temporalidad escatológica y trascendente. Por ello, la tensión entre Apocalipsis e institución de salvación siguió vigente en el cristianismo y, en estos términos, la institución pastoral medieval opta por una escatología anti-apocalíptica ${ }^{34}$.

\section{El modelo escatológico del pastorado medieval}

La contraparte de la economía de salvación personal y jurisdiccional de la Iglesia medieval fue la tendencia hacia una escatología espiritualizada e individualizada. En tanto que la historia de la salvación universal se vincula/depende de la redención de cada uno de los fieles, la Iglesia deviene garante de la recta conducta de los hombres.

31 C. Carozzi, Visiones apocalipticas en la Edad Media. El fin del mundo y la salvación del alma, Madrid, Siglo Veintiuno, 2000, p. 56: "El tiempo que conducía a la escatología del fin de los tiempos cuando Cristo regresará para el Juicio, no era otra cosa que una secuencia de ciclos anuales. La meta perseguida hasta entonces era la conversión de toda la humanidad, y por eso la Iglesia, rechazó enérgicamente los cortes prematuros en el tiempo que había pregonado el montanismo".

32 A. Rivera, "La secularización después de Blumenberg", en Res publica, 11-12, 2003, pp. 95-142, aquí p. 124: "Por todo ello, la Iglesia deja de aguardar con esperanza el final, y pasa a concebir la historia como un "plazo de gracia» (LM, p. 54). Esta Iglesia se convierte ahora en una institución visible o secular que detenta el monopolio de los bienes de salvación, de los sacramentos, con los cuales se apacigua las angustias escatológicas y se prepara a cada uno de los cristianos para superar la sanción divina".

33 H. Blumenberg, op. cit., p. 53: "si se quisiera presentar el proceso que hemos esbozado como una secularización — si bien en un sitio bien distinto del previsto para una secularización — no sería, en todo caso, una mundanización de la escatología, sino una mundanización mediante la escatología".

34 J. L. Villacañas, “Acerca del uso del tiempo apocalíptico en la Edad Media”, en Isegoría, 37, 2007, p. 87: "Durante mucho tiempo el cristianismo estuvo institucionalizado — Iglesia como institución permanente - y mundanizado - Iglesia expansiva en el mundo- y, sin embargo, no se asumieron las tesis de que las promesas de la salvación se pudieran realizar en el tiempo. Ambos aspectos se mantuvieron como preparatorios dentro de un horizonte apocalíptico que clausuraba la historia desde «afuera» del tiempo, afuera desde el cual Dios podría cumplir sus promesas". 
La redención no queda asegurada por la adhesión a la comunidad de fieles o por la participación en los ritos de iniciación, como el bautismo. En contraposición, requerirá de un continuo virtuosismo y una expiación periódica ${ }^{35}$, una conversión continua e interiorizada hacia la perfección de las costumbres.

No por ello la Iglesia renuncia a la escatología ${ }^{36}$. Desde fines del siglo XI, las cruzadas a Tierra Santa, el conflicto papal frente al Imperio y la lucha por erradicar la simonía y nicolaísmo clerical, son fenómenos con una marcada dimensión escatológica. Por ejemplo, en la narración que hace Guibert de Nogent - a posteriori- sobre la proclamación de la cruzada por Urbano II en el Concilio de Clermont, el papa toma el lugar del emperador en un escenario apocalíptico ${ }^{37}$. La toma de Tierra Santa convocada por el Papado pudo ser percibida como el restablecimiento del reino cristiano que antecede al Anticristo y la lucha final. El trasfondo escatológico de las diferentes expediciones de cruzada se manifestó también en la dimensión martirial de los guerreros, en la identificación de los pobres cruzados con los elegidos o en las voces proféticas que definían cronologías apocalípticas vinculando la historia de salvación con la cruzada.

El fracaso de estas expediciones y sus expectativas mesiánicas profundizó el proceso de espiritualización e individualización de la escatología. Las indulgencias plenarias concedidas por el papado y la disposición al martirio de los cruzados sentaron precedentes para identificar la salvación con un proceso vital de penitencia purgativa. La vida cristiana se expresa con el símbolo de la cruzada, como una peregrinación expiatoria de mortificación y piedad. Jerusalén es, cada vez más, la imagen alegórica de la Ciudad celeste, un modelo a imitar y no una tierra a tomar. Cristianización del mundo sí, pero, sobre todo, purificación interna de la Cristiandad latina. Esta es la tendencia del gobierno papal medieval y de su nuevo trasfondo escatológico ${ }^{38}$. La revolución gregoriana también tuvo pretensiones de reformar al propio gobierno eclesiástico corrigiendo ciertas formas de comportamiento clerical, especialmente la simonía y el nicolaísmo, pero también las costumbres y el atuendo. Al diablo se recurrió para condenar tanto a los clérigos no disciplinados como a las tendencias paganas y heréticas dentro de la Cristiandad. En el siglo XIII, el Anticristo deviene para la Iglesia oficial el símbolo de lo que considera una amenaza interna a la cristiandad para la salvación

35 C. Carozzi, op. cit., pp. 55-56: "Se comprende bajo estas circunstancias que la Iglesia no renunciara a la escatología al dirigir la mirada de los creyentes hacia el tiempo corto y la penitencia personal, pues sabía que así aseguraba las bases de una historia de la salvación. Así como contaba cada día, contaba cada individuo".

36 H. Blumenberg, La legitimación de la Edad Moderna, op. cit., p. 53: "Pese al retorno de oleadas escatológico-milenaristas, la Edad Media continuó con esta tendencia a (...) reacuñar el discurso sobre la salvación inminente en una sistemática interiorización de los bienes de la salvación — dejados en manos de la Iglesia, como un inagotable tesoro de gracia, para su administración-. Añádase a esto que la enseñanza unitaria de la escatología se vio escindida en dos. Para la Edad Media, había una escatología cósmica y otra individual".

37 En contraposición a las representaciones que identificaron al emperador germano Enrique IV con la figura también apocalíptica del emperador de los últimos días.

38 J. L. Villacañas, “Acerca del uso del tiempo apocalíptico en la Edad Media”, op. cit., p. 93: "La experiencia apocalíptica desde siempre sirvió no sólo a la política por medio de la herejía, sino a la construcción de poderes y al programa de dominio tano de la naturaleza como de la sociedad. De hecho, la apelación a la experiencia del Apocalipsis siempre jugó en el seno de la aspiración a configurar poderes totales y legítimos, capaces de preparar en la tierra a la segunda llegada de Cristo. Fue desplegada como forma de imponer obediencia desde las instancias legítimas de la sociedad - el Papado o el Imperio - en momentos identificados como crisis total. $\mathrm{Su}$ aspiración a reorganizar la totalidad de la sociedad estaba relacionada con su exigencia de dominio de los recursos materiales a su disposición, dada la razón absoluta de ser la configuración final de la sociedad humana". 
de todo el rebaño ${ }^{39}$. La inclinación al pecado, los residuos de paganismo y el error herético, fueron los principales objetivos a erradicar en tanto elementos diabólicos y corruptores de la salud espiritual de la Iglesia. Identificados como una tendencia en el alma de cada hombre y como individuos y grupos concretos, la Iglesia consideró que estos elementos obstaculizan la preparación para el fin de los tiempos y la salvación de toda la Cristiandad. El acontecimiento más representativo es la cruzada albigense, una guerra santa contra las comunidades cátaras de Occitania condenadas por herejes, para cuya participación se concedieron indulgencias ${ }^{40}$.

Pero las condenas y las quemas por herética parvedad incrementaron en toda la Cristiandad latina ${ }^{41}$, así como otras formas de cristianización correctivas y punitivas —normalización litúrgica, catequización, moralización por predicación, formación sacramental para el clero, iniciación a los sacramentos, etcétera- En este sentido, la Iglesia desarrolla los servicios pastorales de cura de almas, rituales deificadores, entre los que se encuentran los siete sacramentos canónicos que cristalizarán en Trento. Mediante estas prácticas sacramentales de purificación ofrece, además del tiempo lineal y finito de la historia de la salvación que culmina en la eternidad - ausencia de tiempo-, un tiempo cíclico del calendario litúrgico y sacramental, portador de gracia y adecuado a los ritmos agrarios y estacionales ${ }^{42}$. La preparación para el fin de los tiempos deviene un asunto personal y cotidiano que puede realizarse en un calendario sacralizado y repleto de acciones de purgación tales como la confesión, el bautismo, la eucaristía, las oraciones por las almas penitentes del purgatorio, las misas de difuntos, procesiones, peregrinaciones, etcétera. Confesión, purgatorio e indulgencias, se fundamentan sobre la idea de que es posible la expiación del pecado en el mundo a través de la mediación canónica. Esa idea está vinculada a una concepción de la justicia papal en analogía a la justicia divina, en definitiva, a la divinización de la función pontifical ${ }^{43}$. En el momento en que el papado se abroga la capacidad para juzgar la conciencia, tienden a coincidir el foro interno y el externo, el del pecado y el del crimen, el de la purgación y el de la punición, el de la justicia divina y el de la justicia eclesiástica ${ }^{44}$. Hasta entonces, el pecado oculto había sido considerado un terreno

39 C. Carozzi, op. cit., p. 100: "Era preciso sacar de la guarida al Anticristo, esto es, al Diablo, y aniquilarlo para que no pusiera en peligro la necesaria obra de expiación purificadora. El hombre cristiano se hizo cada vez más un individuo penitente. La introducción de la confesión personal y secreta en el cuarto concilio lateranense (1215) fue uno de los resultados de esta tendencia. De ello resultó que la salvación individual y colectiva de los cristianos era solo un asunto de la Iglesia; el imperio quedaba de hecho fuera de juego".

40 La herejía llega a ser identificada por Inocencio III como crimen de lesa majestad, como había establecido el Emperador Diocleciano unos 600 años antes, pero ahora se trata de un crimen contra la Iglesia. Que la herética parvedad sea equiparada con un crimen suponía que podría ser penada por vía criminal en lugar de ser corregida sólo por vía purgativa o penitencial — propia del foro interno de la conciencia.

41 Se trata de una novedad puesto que, desde el final del imperio romano hasta la quema en la hoguera de Colonia a finales del siglo XII, no hay indicios de quemas sistemáticas de herejes.

42 Carozzi, op. cit., p. 53.

43 Cf. K. Pennington, "Popes, Canonists, and Texts 1150-1550”, en Collected Studies Series 412, Aldershot, Variorum, 1993.

44 P. Prodi, Una storia della giustizia: dal pluralismo dei fori al moderno dualismo tra coscienza e diritto, Bologna, Società editrice il Mulino, 2000, pp. 59-63. Para Gregorio VII, la justicia divina deviene la norma absoluta de referencia de todo comportamiento humano, cuya encarnación recaería en la institución histórica de la Iglesia. El papado es ahora no sólo el garante del derecho, sino juez omnipotente. Las colecciones canónicas, entre 1070 y 1140, recogen esta idea cuya culminación es el Decretum de Graciano. El poder de las llaves es ahora un poder también para juzgar la riqueza o el dominio territorial; durante el siglo XII se des-diferencian el poder de sacerdocio y el de jurisdicción dentro del poder de las llaves de la Iglesia. 
inasible para los hombres y prerrogativa exclusiva de la cognición divina. Ahora, el gobierno papal promueve el examen de conciencia, la confesión obligatoria y el procedimiento judicial de la inquisición para desvelar el pecado oculto ${ }^{45}$.

La Iglesia permite y obliga a los hombres a purgar sus pecados en el más acá y, para ello, promueve y canaliza el anhelo de un comportamiento virtuoso y la predisposición a la purgación penitente ancladas en el temor a la condena final ${ }^{46} \mathrm{y}$ en la conciencia de pecado. La confesión auricular - anual, individual y al propio párroco, que se instituye como obligatoria en el IV concilio lateranense en 1215- debe enmarcarse en esta economía de salvación que ofrece la Iglesia medieval. Se trata del nuevo sacramento de la penitencia que Foucault analiza reiteradamente. Como servicio de cura animarun, responde a la interiorización de la culpa y espiritualización de la penitencia. Se basa en el reconocimiento de una inclinación personal al pecado, no siempre visibilizado e incluso oculto a uno mismo que produce pavor ante la imagen de la justicia divina ${ }^{47}$. De hecho, el sacramento de la penitencia por confesión al párroco hace de la mala conciencia, el arrepentimiento o contrición, el fundamento para la absolución. A diferencia de lo que ocurría en la antigua penitencia pública, donde la absolución divina - y no clerical - derivaba de una acción purgativa corporal, colectiva y pública, ahora se trata de apaciguar el temor, purificar el alma y dominar el diablo ${ }^{48}$.

\section{Contra-modelos escatológicos y salvíficos}

Esta nueva economía de salvación eclesiástica entra en disputa por la legitimidad pastoral con vías de salvación que preexistían a la reforma en las microcristiandades $^{49}$ y con otras que surgen durante los siglos XI al XII ${ }^{50}$. Este periodo está marcado por una crisis en el corazón franco-romano de la cristiandad debido a la fragmentación de las potestades jurisdiccionales y la arbitrariedad de la violencia de la nueva aristocracia guerrera que se impone tras la decadencia de la autoridad

45 Cf. J. Chiffoleau, La Chiesa, il segreto e l'obbedienza. La costruzione del soggetto politico nel medioevo, Bolonia, Il Mulino, 2010.

46 Le Goff. La civilización del occidente medieval, op.cit., p. 165: "El Occidente medieval, en esa espera de la salvación, es el mundo del miedo ineludible. En esta larga historia de un miedo elaborado poco a poco doctrinalmente y vivido visceralmente de generación en generación, señalaremos algunos ejemplos".

47 A. Rivera. "Blumenberg y el debate sobre la secularización": en Eikasía. Revista de Filosofia, 45, 2012, pp. 237-244, aquí p. 240.

48 Le Goff, La bolsa y la vida. Economía y religión en la Edad Media, Barcelona, Gedisa, 2003, pp. 99-100: "Alrededor del año 1000 se produjo un gran cambio que nosotros llamamos feudalidad. (...) La Iglesia (...) se esforzó por cristianizar verdaderamente a la sociedad y lo hizo de conformidad con los métodos habituales en los poderosos: la zanahoria y el palo. El palo fue Satanás. Llegado desde el lejano y profundo Oriente, el diablo fue racionalizado e institucionalizado por la Iglesia y fue una figura que funcionó bien alrededor del año mil. El diablo, azote de Dios, general de un ejército de demonios bien organizados, amo en sus territorios, el infierno, fue el director de orquesta del imaginario feudal. Pero el diablo sólo podía ofrecer - puesto que Dios en el paraíso forzosamente no admitía más que una minoría de perfectos, de santos - un más allá sin esperanzas a una sociedad que lograba cada vez menos pensar según el modelo estrictamente antagónico de los buenos y de los malos, de lo blanco y de lo negro. (...) La zanahoria fue el purgatorio. El purgatorio nace al final de esta gran transformación querida por la iglesia como una modificación de toda la sociedad: la reforma gregoriana".

49 J. A. García de Cortázar, Historia religiosa del Occidente medieval (Años 313-1464), Madrid, Akal, 2012, pp.149-241.

50 J. Le Goff, La civilización del Occidente medieval, op.cit. Barcelona, Paidós, 2008, pp. 160-170. 
imperial carolingia. También fueron tiempos difíciles en las periferias gracias a la cristianización abrupta, las incursiones de húngaros, vikingos y sarracenos y la extensión del proceso de feudalización ${ }^{51}$. Durante el siglo XI — siglo de la revolución papal y la reforma moral - prosperaron líderes carismáticos cuyo comportamiento ejemplarizante atraía a seguidores entre sus comunidades, así como tendencias heterogéneas en pro de un pauperismo voluntario, de experiencias penitenciales purgativas y afanes de virtuosismo moral a imitación de las enseñanzas evangélicas. La reforma moral gregoriana intentó canalizar canónicamente parte de estos anhelos que, en ocasiones, se vieron frustrados al tiempo que se absolutizaba y burocratizaba el gobierno papal. La alianza de pauperes e Iglesia en las Paces de Dios también terminará fracasando, al mismo tiempo que tienen lugar cambios abruptos ${ }^{52}$ relacionados con la emergencia de una nueva economía agraria y un proceso de urbanización que imponen una la división social del trabajo más compleja, así como una progresiva mercantilización y monetización de los intercambios ${ }^{53}$. Desde el siglo XII se hacen visibles movimientos organizados en los márgenes o al margen de la Iglesia con afán de asegurar su salvación por otras vías ${ }^{54}$. Algunos actualizan mitologemas del Apocalipsis donde el papado, el imperio o las órdenes mendicantes, son identificados con las figuras apocalípticas del emperador de los últimos días, el Anticristo o los profetas Elías y Eón ${ }^{55}$.

Foucault ha caracterizado a algunos de estos movimientos límites internos del pastorado cuando sus puntos de resistencia caen principalmente dentro del campo pastoral, es decir, cuando aspiran a ser guiados a la salvación por otros medios ${ }^{56}$. Los ha clasificado en cinco tipos de contra-conducta pastoral: ascetismo, comunidad, mística, escritura y creencia escatológica ${ }^{57}$. Los cuales se diferencian de los límites externos que serían aquellas rebeliones contra el pastorado eclesiástico que anclan sus resistencias en rasgos propios del modelo soberano como los judiciales o feudales. Históricamente las identifica con la brujería, los elementos paganos de las comunidades en proceso de cristianización y la gran herejía cátara que habría constituido un pastorado no propiamente cristiano. Sin embargo, la diferencia entre la contra-conducta y la anti-pastoral se sostiene difícilmente desde la historiografía y desde el marco heurístico de la economía escatológica de salvación trinitaria. Por un lado, la cristianización a la romana de las costumbres devocionales y litúrgicas es un fenómeno tardío, que se expande en la cristiandad latina fundamentalmente entre los siglos XI y XIII. Esto implica que durante este periodo la distinción entre las supersticiones no cristianas - ritos paganos, magia, brujería, etcétera-y las creencias cristianas

\footnotetext{
Cf. M. Bloch, La sociedad feudal, Madrid, Akal, 1988.

Cf. R. Moore, La primera revolución europea: C. 970-1250, Barcelona, Crítica, 2003.

Le Goff. La Edad Media y el dinero, Madrid, Akal, 2012, p. 47.

54 M. Lambert, Medieval Heresy: Popular Movements from the Gregorian Reform to the Reformation, Oxford, Blackwell, 2003, p. 39.

55 Cf. N. Cohn, En pos del milenio. Revolucionarios milenaristas y anarquistas místicos de la Edad Media, Logroño, Pepitas de calabaza, 2015.

56 Foucault, Seguridad, territorio y población, op. cit, pp. 188-199.

57 Aquí Foucault identifica claramente la creencia escatológica con el milenarismo y la temporalización al plantear que consiste: "Después de todo, la otra manera de descalificar el papel del pastor consiste en afirmar que los tiempos se han consumado o están a punto de consumarse, que Dios va a volver o está punto de volver para juntar su rebaño. (...) o bien, en otra forma de escatología, desarrollada en todo el linaje que deriva de manera más o menos directa de Joaquín de Fiore, porque se afirma la aparición de un tercer tiempo, una tercera época en la historia". M. Foucault, Seguridad, territorio y población, op. cit., pp 215-216.
} 
oficiales esté todavía en permanente negociación, en la que intervienen los saberes vernáculos de estas resistencias a la Iglesia - tanto las contra-conductas como las anti-pastorales ${ }^{58}$ - . Por otro lado, como hemos argumentado anteriormente, cualquier pastorado cristiano dispone de una política y una economía de salvación por la que se define también la relación de la comunidad de fieles con el resto profano de poder; esto hace que las resistencias a los vínculos feudales eclesiásticos, a la riqueza, a su potestad jurisdiccional, etcétera, no tengan por qué ser anti-pastorales.

Así, lo que Foucault considera que tienen en común las contra-conductas, el hecho de que quieran ser guiados a la salvación de otro modo - o resistirse a la conducta eclesiástica - es un rasgo que presentan también las costumbres paganas de las comunidades cristianas o las herejías que constituyen una Iglesia propia como el catarismo y, en cierto modo, los valdenses. Hay en todas ellas una tendencia a conformarse como contra-economías de salvación o contra-poderes pastorales cuando se racionaliza la historia de la salvación como una disputa por la interpretación de la escatología de los agentes y la cronología. Por ello, afectan en distinto grado a algunos fundamentos de la teología trinitaria, principalmente, cuando se pone en cuestión el papel de la Iglesia como vicario de Pedro y como locus deificador en el tiempo ${ }^{59}$. El estudio de los rasgos de estos movimientos lo pone de manifiesto.

Entre los líderes carismáticos del siglo XI que hallaron una forma de canalizar su contra-economía dentro de la oficialidad de la Iglesia está Norberto de Xanten ${ }^{60}$. Fue un clérigo ordenado que decide comenzar una vida apostólica y será seguido por grupos pietistas en su actividad predicadora. En 1119 el papa Calixto II le solicita que funde una orden religiosa para albergar a sus adeptos en la diócesis de Laón, que será aprobada por Honorio II en 1125 como la orden de Prémontré - llamados canónigos blancos o premostratenses-, regida por la regla de San Agustín. Otro líder cuyas polémicas prácticas ascéticas tuvieron cabida dentro de la Iglesia papal fue Roberto de Arbrissel a finales del siglo XI. Era hijo y nieto de sacerdotes, pues el sacerdocio era todavía un oficio hereditario en la época en Bretaña - y otros lugares de Europa- a pesar de las prohibiciones conciliares a principios de siglo y estudió en París. En la diócesis de Rennes fue encargado de promover la implementación de la reforma eclesiástica, especialmente la supresión de la simonía promovida por la reforma gregoriana, lo que suscitó una fervorosa animadversión dentro de las filas clero local. En con-

58 Le Goff, La bolsa y la vida, Barcelona, Gedisa, 2003, pp. 97-100: “[Antes de la cristianización eclesiástica de la feudalidad occidental entre los siglos XI y XIII muchos hombres y mujeres] (...) vivían en una sociedad incompletamente cristianizada en la cual la religión había tal vez impuesto su ley en la superficie de los seres y de las cosas, pero no había penetrado todas las conciencias y todos los corazones. (...) Verdad es que estaban Dios y el juicio final. Pero los hombres no llegaban a establecer una relación estrecha entre su propia vida y lo que sería el juicio de Dios que les esperaba. Ese Dios se parecía a los dioses sedientos a quienes habían adorado durante mucho tiempo sus antepasados, fuerzas de la naturaleza (...); era un Dios enteramente diferente, pero a quien las masas laicas, superficialmente cristianizadas, trataban de satisfacer con las mismas ofrendas o los mismos donativos nuevos que se parecían a los antiguos. (...) Dios estaba representado en la tierra por sus santos y por la Iglesia".

59 J. L. Villacañas, “Acerca del uso del tiempo apocalíptico en la Edad Media”, op. cit., p. 84: "Sin embargo, la expansión cristianizadora y la introducción del vector de futuro, no disolvieron el germen negador del mundo y la aspiración acósmica. En ese momento del paso de la Iglesia militante a la triunfante, se alojó el germen acósmico cristiano y desde él regresó con fuerza y se impuso sobre las mediaciones institucionales".

60 R. Moore. La guerra contra la herejía, op. cit., pp. 149-153. Hijo de un conde, estuvo en la corte de Enrique $\mathrm{V}$ que abandonó para llevar una vida penitente después de sufrir un accidente, entonces funda una abadía y es ordenado sacerdote. 
secuencia, abandona su diócesis hacia Angers donde comienza una vida ermitaña en el bosque Craon de Anjou, donde predicaban muchos ermitaños huidos de las estructuras eclesiásticas de poder. Posteriormente, a solicitud del papa Urbano II, Robert predicó en el sudoeste de Francia, donde con un estilo ermitaño particular cosechó numerosos devotos. Es probable que estos no fueran los esperados por el papado, puesto que gran parte de sus partidarios fueron figuras marginales de la época tales como leprosos, pobres y prostitutas, a quiénes acogía en la abadía de Fontevraud en una casa dedicada a santa Magdalena. Las actividades de estos líderes fueron canalizadas en nuevas organizaciones eclesiásticas gracias a la aprobación papal — como ocurrirá posteriormente con los franciscanos-, a pesar de sus desavenencias con el clero diocesano. No obstante, existieron también otros predicadores ambulantes que traspasaron la línea de la oficialidad, en parte porque su exaltada contra-economía salvífica identificaba la Iglesia romana con la figura apocalíptica del Anticristo. Eudo de Stella o Tanquelmo ${ }^{61}$ se presentaron como nuevos mesías a imagen de Elías y Enoc, mientras predicaban que el Anticristo había nacido ya y residía en la Iglesia romana. Como preparación para la lucha final, exhortaban a la quema de parroquias y a acciones violentas contra el clero ordenado y los bienes eclesiásticos.

También Pedro de Bruys ${ }^{62}$ y Enrique de Laussana ${ }^{63}$ se presentaron como nuevos profetas en el siglo XII en la actual Francia. Ambos provenían del propio estamento clerical, pero acabaron afirmando que el culto de la Iglesia era una ilusión diabólica,

61 M. Lambert, Medieval Heresy: Popular Movements from the Gregorian Reform to the Reformation, Oxford, Blackwell, 2003, pp. 40-42.

62 Lo que conocemos de Pierre du Bruys es gracias a un tratado del abad de Cluny, Pedro el Venerable - Tratado contra los pretrobrusianos - y a un pasaje escrito por Pedro Abelardo. Según estos textos, fue un sacerdote ordenado de Provenza que fue depuesto y predicó por las tierras del sur de la actual Francia. En sus sermones criticaba el poder señorial de los obispos, impugnaba la vía de salvación de las autoridades eclesiásticas y la utilidad de los sacramentos, administrados por sacerdotes indignos. En oposición, afirmó que la fe es suficiente para asegurar la redención futura. Alentó a la destrucción de templos, a la quema de cruces y, fundamentalmente, a oponerse al pago de diezmo y al comercio de indulgencias. Fue depuesto por estas prédicas y, en las diócesis cercanas, sus enseñanzas fueron prohibidas. No por ello dejó de suscitar partidarios — los petrobrusianos-, principalmente en los entornos de Narbona, Toulouse y Gascuña. Sus prédicas están centradas en la vida de Cristo según una lectura de los Evangelios que no se inserta en la tradición exegética de la patrística y que elude el Viejo Testamento_Según Pedro el Venerable, rechazó el bautismo de infantes, la gracia sacramental, la adoración de las cruces, el purgatorio, el celibato clerical y los templos o edificios como lugares sacros, entre otros. Bernardo de Clavaral lo persigue y será condenado en el Concilio de Tolosa de 1115. Fue linchado hasta la muerte por una facción, alentada por Cluny, en una emboscada en Saint-Gilles donde predicaba hacia 1126. R. Vaneigem, Las herejías, México, Ed. Jus, 2008, pp. 100-102; R. Moore, La guerra contra la herejía, op.cit., pp. 144-147.

63 Se cree que Henri du Mans - Enrique de Lausana - fue discípulo de De Bruys. Fue un líder carismático o agitador en luchas comunalistas urbanas contra la jerarquía eclesiástica y la aristocracia terrateniente. Para Venengein estos movimientos están relacionados con la progresiva emergencia del capitalismo y el mundo urbano - las ciudades - contra los poderes señoriales, incluso supongo de los obispos. Fue monje benedictino, ordenado en la abadía de Cluny, predicó en Lemans a principios del siglo XII y, luego, por todo el sur de la Francia actual. Rechazaba también la mediación de la jerarquía eclesiástica, el culto a los santos y la liturgia romana. Se presentaba como un ermitaño o pobre evangélico — pelo largo, barba, descalzo - y proponía una vida de piedad y purificación; durante sus sermones, el público llevaba a desprenderse de sus bienes muebles quemándolos en hogueras. Finalmente, acabó siendo arrestado por el arzobispo de Arles, Bernard Garin, y obligado a renegar de sus doctrinas y recluirse en el monasterio de Citeaux, en el Concilio de Pisa de 1135. Sin embargo, retomó la predicación por las zonas de Toulouse, lo que provocó que Bernardo de Claraval insistiera al Conde de Sant-Gilles de que lo condenaran y arrestaran. Así, fue declarado heresiarca de en el concilio de Letrán de 1139 y en Reims en 1148; arrestado y puesto en presión de por vida a instancias del papa Eugenio III. R. Vaneigem, Las herejías, México, Ed. Jus, 2008, pp. 100-102; R. Moore, La guerra contra la herejía, op.cit., pp. 162-163. 
de modo que predicaron contra la gracia sacramental, la imposición del diezmo y el purgatorio. Como alternativa a la vía salvífica eclesiástica, promovieron un comportamiento que mimetizara el martirio de Cristo profetizando que era parte de la lucha final contra el Anticristo que identificaban con los sacramentos y monumentos eclesiásticos.

Desde la mitad del siglo XII, algunas contra-economías se identificaron con la verdadera Iglesia como iglesia de los espirituales, frente a la oficial ${ }^{64}$ que equiparaban con la iglesia carnal o del demonio. Es entonces cuando comenzó a estandarizarse un procedimiento jurídico con tribunales eclesiásticos para condenar a herejes $\mathrm{y}$ entregarlos al poder secular para su castigo ${ }^{65}$, para posteriormente sistematizarse su persecución. Algunos precedentes están en los movimientos de Orleáns ${ }^{66} \mathrm{o}$ Monteforte ${ }^{67}$, quienes fueron acusados de dualistas porque entendían que el camino de salvación suponía el rechazo de lo mundano: abstinencia sexual y de ingesta de carne, prescindir de los monumentos, sacramentos y objetos litúrgicos eclesiásticos. Han identificado ya al Anticristo en la Iglesia romana y se contraponen a ella como el rebaño de los elegidos, identifican la iglesia del diablo con la jerarquía eclesiástica y pretenden instaurar un reino de los espirituales en la tierra. En el conflicto con las autoridades eclesiásticas defendieron sus doctrinas y rehusaron obstinadamente la vuelta al seno de la Iglesia, igualmente, acataron el castigo en la hoguera con una disposición martirial que fascinó a sus contemporáneos, pues se mostraban convencidos de su salvación como iglesia de los elegidos.

El caso de los valdenses ilustra la fragilidad de la frontera que hizo de estos movimientos herejes o que los integró como órdenes dentro de la Iglesia como a los franciscanos ${ }^{68} ; \mathrm{y}$ también la del criterio que diferencia las contra-conductas de las

64 C. Carozzi, op. cit., p. 78.

65 R. Moore, La guerra contra la herejía, Barcelona, Planeta, 2004, p. 24: "Aunque ahora se piense comúnmente en la quema de herejes como un recurso ordinario, incluso rutinario, de la sociedad medieval, de hecho, no fue así hasta finales del siglo XII".

66 El movimiento de Orleans, liderado por clérigos formados a principios del siglo XII, el principal conflicto con la ortodoxia fue su concepción de la figura de Cristo y, en consecuencia, el lugar de la Iglesia en la historia de la salvación. Rechazaron la idea trinitaria de que Cristo dispusiera de un cuerpo humano, que naciera de la Virgen y sufriera por los hombres. Ni había sido sepultado, ni habría resucitado; en consecuencia, rechazaban el bautismo y la penitencia como formas de expiación de pecados, así como la capacidad clerical de administrar la gracia por ordenación canónica. Su contra-salvación se fundamentaba en una iluminación interna, cercana a la gnosis. Tras un juicio con obispos y reyes, se mostraron obstinados en sostener su doctrina y rechazaron la vuelta a la Iglesia. Por ello, fueron quemados en hogueras — excepto dos que se retractaron-. M. Lambert, Medieval heresy, op.cit., pp. 76-78.

67 La herejía de Monteforte fue principalmente laica. También tuvieron elementos iluministas, comportamientos ascéticos — castidad y ayunos - y cuestionaron abiertamente la autoridad papal; rechazaron el bautismo y la expiación del pecado puesto que condenan la mediación expiatoria que, para ello, es fruto de una relación directa con Dios. En Aquitania también rechazan bautismo y el poder de la cruz, la Iglesia y el redentor. Las fuentes católicas les acusaron de maniqueos.

68 La aprobación de la regla franciscana por el papado en 1209 además de integrar los anhelos de este movimiento de pobreza voluntaria dentro de la Iglesia, da lugar a la creación de una nueva orden que los situaba entre el clero secular y el regular. La actividad proselitista de las órdenes mendicantes — también la de la orden dominica o frailes predicadores - presenta numerosas analogías con la llevada a cabo por los líderes carismáticos anteriormente mencionados. Se trata de una catequesis ejemplarizante a través de un modo de vida austero que renuncia a la posesión de bienes, pero no se apartar de la vida urbana — no es una fuga mundi-. La actividad catequética se basada una enseñanza moral — de los vicios y virtudes cristianas - mediante la prédica de sermones escolásticos y a través de la ejemplaridad de una vida virtuosa y lejos del ostento de riqueza. Estas órdenes desempeñaron un papel importante en la tarea de cristianización y erradicación de los errores heréticos; 
anti-pastorales que organizan un pastorado propio como ocurrió con el catarismo. Valdo era un mercader rico de Lyon que, tras consultar a un teólogo, decide donar todos sus bienes y comenzar una vida de pobreza voluntaria evangelizadora. Pronto entró en conflicto con el arzobispo, puesto que la ley canónica sólo permitía predicar a clérigos ordenados y formados; la predicación fue uno de los locus recurrentes de confrontación entre estos líderes comunitarios carismáticos y las autoridades eclesiásticas. Ante la prohibición episcopal, Valdo apela al papa Alejandro III que, tras un examen teológico, le ordena que acate la decisión del obispo. Sin embargo, Valdo y sus seguidores continuaron predicando y serán excomulgados en 1184 en el concilio de Verona, por pertinaces y cismáticos ${ }^{69}$ al rechazar los poderes sacramentales de la Iglesia. Desarrollaron, en cierto modo, un pastorado propio en el que se diferenciaban funciones pastorales y proselitistas y se reunían clandestinamente en pequeños grupos congregados en torno a predicadores ambulantes. En estas reuniones los participantes se confesaban directamente ante Dios y celebrar un servicio divino comunitario, sin intermediarios sacerdotales. Cuestionaron la legitimidad de la Iglesia romana como heredera de Pedro y, con ello su papel mediador entre Dios y los hombres y su capacidad de administrar el pneuma. No obstante, posteriormente, una de las escisiones valdenses liderada por Durand de Huesca se reconcilió con la Iglesia y constituyó la orden de los Pobres Católicos aprobada por Inocencio III en 1208. Este grupo participó en la lucha contra los cátaros y se cree que su líder escribió un tratado - el Liber contra Manicheos - defendiendo sus postulados frente al de los herejes cátaros.

Hemos ofrecido pinceladas de algunos ejemplos de caminos salvíficos diversos de los numerosos que encontramos en el periodo plenomedieval que, por razones de espacio, no podemos explorar. Sin embargo, son suficientes para ilustrar algunos rasgos comunes que les posicionan como contra-economías de salvación ante la Iglesia romana. Una tendencia común es la impugnación del poder deificador de los sacramentos eclesiásticos y de la administración clerical del pneuma. Esto pone en cuestión el papel la legitimidad de la intersección eclesiástica ante Dios y su guía hacia el horizonte del juicio final, así como la sacralidad de sus monumentos y los objetos sacramentales y litúrgicos, tales como las parroquias o el pan y vino en la eucaristía ${ }^{70}$. Otro tema recurrente es el alejamiento de la institución eclesial romana

lo hicieron desde una organización universal al no estar adscritos a la estructura territorial diocesana y depender directamente de la autoridad papal — que le otorgaba numerosas inmunidades y privilegios frente a los poderes obispal y monástico- . Desempeñaron, además, un papel muy activo en las nacientes universidades y en la difusión de los saberes escolásticos por toda la cristiandad gracias a gran la movilidad de estos escolares y de sus manuscritos.

69 Los valdenses pusieron en cuestión abiertamente la capacidad mediadora de la Iglesia romana argumentando que esa potestad desaparece con la muerte de Cristo y, por ello, no puede ser objeto de herencia apostólica. Desde esta perspectiva, rechazaron innumerables prácticas pastorales y litúrgicas de la Iglesia romana tales como: la veneración a imágenes, reliquias o crucifijos, el fenómeno de la transubstanciación en la eucaristía, la existencia del purgatorio y la capacidad redentora de las indulgencias y las misas por difuntos, la veneración a María, las oraciones a los santos, la competencia clerical para absolver pecados en confesión o el bautismo de niños.

70 Pedro el Venerable en su tratado contra los seguidores de Du Bruys, pone en su boca las siguientes palabras, en las que se manifiesta su rechazado a la eucaristía y la transustanciación: "Oh, gente, no creáis en los obispos, sacerdotes o clérigos que os seducen; que, como en muchas cosas, tanto en su oficio como en el altar, os engañan cuando profesan falsamente que hacen el cuerpo de Cristo, y os lo dan para salvar vuestras almas". Pedro de Cluny, “Tractatus Contra Petrobrussianos”, en Patrologia Latina, 189, (ed.) J.-P. Migne, París, Vivès, 1980, pp. $720-850$. 
del legado de Cristo y su ilegitimidad como vicario de Pedro. Muchos de estos movimientos creen que la vía salvífica consiste en la mímesis de la vida evangélica de las enseñanzas de Cristo, sin necesidad de la mediación canónica ${ }^{71}$. La relación de los movimientos del siglo XI, mayoritariamente espontáneos y reformadores, con la autoridad eclesiástica muestra que se mueven en los límites de la oficialidad donde el margen entre dentro y fuera es muy estrecho. No será hasta el siglo XII cuando se visibilicen tendencias hacia la racionalización y organización de contra-economías de salvación, al tiempo que se desarrolla una política antiherética desde el pastorado oficial. Serán condenadas y perseguidas como herejía aquellas doctrinas y organizaciones que desafían el rol del gobierno papal como vicario de Cristo y rehúsan a participar en la economía eclesiástica y organicen vías alternativas hacia la redención en el tiempo final. Lo que ocurrió con ciertas corrientes de valdenses, de cátaros y con la doctrina de Joaquín de Fiore en el IV Concilio de Letrán que ya anticipaba la amenaza de los futuros joaquinistas al anunciar una tercera era del espíritu en la que la institución eclesiástica no tendrá papel alguno en la salvación.

\section{Conclusiones}

Los ejemplos de los saberes vernáculos — propios de una perspectiva genealógica- muestran las coordenadas en las que se mueve el conflicto en el cristianismo medieval: la forma que adopta la política escatológica y la economía de salvación de la organización de la comunidad cristiana. A pesar de la desarrollada institucionalización y mundanización de la Iglesia romana plenomedieval, la disputa se localiza en los márgenes del marco de la teología trinitaria inaugurada en los albores del cristianismo. Los saberes sometidos contestan la posibilidad de una teocracia papal o absolutización del poder temporal de la autoridad espiritual; es decir, su existencia puso en cuestión la legitimidad de una potestad cristiana que no respete la existencia de un resto profano de poder en el tiempo, mientras el plan salvífico de Dios no llega a realizarse en su totalidad. El trasfondo escatológico está presente en las contra-conductas pastorales y en la organización real del pastorado eclesiástico -como plantea Foucault cuando se refiere a la temporalidad medieval-. En definitiva, lo que está en juego en la dinámica entre la Iglesia y las contra-economías de salvación es la legitimidad de la administración del pneuma y, por tanto, la posibilidad de participar en la manifestación del reino divino en la tierra a través de la mediación canónico-eclesiástica.

Desde esta perspectiva, el pastorado cristiano se revela como un poder gubernativo y político al mismo tiempo, en tanto que su potestad se funda en una experiencia al mismo tiempo trascendente e inmanente. El gobierno pastoral es una potestad constitutivamente dual porque se organiza en función de una decisión sobre cuándo y cómo se producirá la salvación del conjunto de la cristiandad y de cada uno de los fieles -omnes et singulatim - . La política escatológica organiza el tiempo de salvación mediante una economía salvífica concreta que produce efectos institucionales y jurídicos reales mediante los que condiciona las costumbres de los hombres, conduce las almas y organiza bienes, territorios y riquezas. Históricamente, esto dio

${ }_{71}$ M. Lambert, op. cit., p. 6. 
lugar a una progresiva jurisdiccionalización de la administración de la cura de almas y a una sacralización del gobierno eclesial que culmina en los siglos centrales de la Edad Media. El despliegue papal de una política anti-herética de erradicación y de una cristianización forzosa se fundó sobre esta dualidad política y gubernativa del pastorado, en una absolutización de su potestad que empujó al máximo los límites pastorales.

Al estar basada en la contraposición entre el gobierno y soberanía e identificar al cristianismo solamente con el primero, la categoría del poder pastoral de Foucault no permite aprehender la tendencia jurisdiccional que implicó la constitución de la Iglesia. Los saberes sometidos, el anhelo de otras vías de salvación, ponen de manifiesto que la dinámica entre ley y conducta — gobierno y soberanía - atraviesa el cristianismo y afecta a la Iglesia romana incluso en su momento máximo de mundanización. Por ello, las resistencias a la Iglesia se localizan en los márgenes tanto del campo de la conducta de almas como del campo de su organización jurisdiccional y feudal. El pastorado cristiano medieval no es una hybris porque en su dualidad gubernativa y soberana no hay escisión entre esferas separadas; la racionalidad escatológica y la economía salvífica que atraviesa la temporalidad medieval hace del cosmos - espiritual y temporal — un lugar unificado. 